Revista Espaço do Currículo

ISSN 1983-1579

Doi: 10.22478/ufpb.1983-1579.2019v12n3.46682

http://periodicos.ufpb.br/ojs2/index.php

\title{
CURSOS DE LICENCIATURA EM ARTES VISUAIS NA BAHIA: diálogos entre UFBA, UNIVASF e UFOB
}

\author{
VISUAL ARTS TEACHERS EDUCATION AT BAHIA: dialogues between UFBA, UNIVASF and UFOB
}

Flávia Maria de Brito Pedrosa Vasconcelos ${ }^{1}$

Resumo: Este texto busca descrever e aprofundar relações de construção dos currículos das licenciaturas em Artes Visuais na Bahia, tendo como foco encontros e discussões assim como analisar conceitualmente sobre o que vem a ser o currículo desde as Diretrizes Curriculares Nacionais homologadas em 2015. Por fim, busca tecer laços interinstitucionais entre UFBA, UNIVASF e UFOB na revisão sobre a formação de professores de Artes Visuais no estado, de forma não somente a atender perspectivas contemporâneas, mas de promover um espaço amplo de formação que reflita como caminho crítico no exercício e na responsabilidade da formação de professores para espaços formais e não-formais de ensino.

Palavras-chave: currículo, formação de professores de Artes Visuais, Arte/Educação.

\begin{abstract}
This text intends to describe and deepen relations of curricula construction of the Visual Arts Education graduations in Bahia, focusing on meetings and discussions as well as analyzying conceptuallly understandings what has become the curriculum since the National Curricular Guidelines approved in 2015. Finally, search interinstitutional ties between UFBA, UNIVASF and UFOB in the review on the formation of Visual Arts teachers in the state, not only to agree with contemporary perspectives, but to promote a broad education space that reflects as a critical path in the exercise and responsibility of teachers formation for formal and non-formal educational spaces
\end{abstract}

Keywords: curriculum, Visual Arts Teachers Education, Art/Education.

\section{SOBRE O CURRÍCULO E AS DIRETRIZES CURRICULARES NACIONAIS DE 2015}

A palavra currículo delimita um conjunto de normas que devem ser seguidas em um percurso de formação, tendo suas raízes e sua maior formatação a partir da criação do sistema escolar e do movimento de escolarização formal, que destinava um tipo específico de conteúdo para a população em geral em finais do século XIX.

Esse processo de escolarização, como todo processo educacional, foi construído em um sistema de "controle social por um lado, e de livre cooperação, [...] ambos a serviço da 'boa sociedade' concebida como uma estrutura corporacional altamente organizada e pacificamente produtiva." (ILLICH, 1985, p. 78). Com isso, as escolas foram o meio pelo qual socialmente um tipo específico de ensino/aprendizado era esperado dos professores e um tipo específico de conteúdo, habilidade e competência era justificado para ser desenvolvido e/ou adquirido pelo aluno, o que tradicionalmente foi pautado em uma relação de poder entre quem professa o conhecimento (professor) transformado em conteúdos escolares e quem recebe passivamente e memoriza o que é ensinado (aluno).

Dessa maneira, no processo de escolarização dos indivíduos, as tensões entre saberes e fazeres do cotidiano de estudantes e professores deixam de fazer parte fundante do currículo, seguindo-se uma

\footnotetext{
${ }^{1}$ Doutora em Educação Artística pela Universidade do Porto - Portugal. Professora da Licenciatura em Artes Visuais da Universidade Federal do Vale do São Francisco - UNIVASF. E-mail: flapedrosa@gmail.com. ORCID: http://orcid.org/0000-0001-9853-5588.
} 
quantidade de conteúdos a serem assimilados em um ambiente em que não se privilegia a reflexão crítica. Sendo assim,

Ao restringir o espaço de reflexão à escolarização formal, sujeitos e saberes estão claramente delimitados: professores e alunos e o conhecimento tido como 'científico'. Sujeitos que ocupam lugares sociais delimitados e, desse modo, mais do que responderem por si mesmos, veiculam, através de suas falas, posturas e gestos, vozes sociais que expressam a história socialmente produzida desses lugares. (ZANELLA, 2008, p. 87).

Por essa razão, o conhecimento da norma, hegemônico, indicado pelo autor supracitado como científico, faz parte de uma interpretação sobre a sociedade estandardizada, idealizada por quem produz e promove as políticas públicas educacionais. Por isso, ao olhar com mais profundidade para os meandros do currículo, pode-se deparar com a demarcação de territórios que evidenciam, como destaca Michel Foucault em sua obra Microfísica do Poder (2007), uma manipulação pelo discurso de quem detém o saber. Assim, podemos inferir que a construção do conhecimento é regulada, ao compartimentar conhecimento em conteúdos numa perspectiva acrítica para as massas.

Mesmo diante de um currículo que é pensado para as massas e com uma definição limitadora sobre o que é o processo de ensino/aprendizagem assim como dos conteúdos contextualizados diante de um território de diferentes culturas como é o Brasil, observamos que nos últimos trinta anos a teoria, a legislação e a prática das políticas educacionais tem se distanciado da realidade, do chão da sala de aula das escolas.

Neste sentido, é fundamental refletir sobre o tempo em que vivemos, na consciência de que atravessamos um momento histórico no Brasil em que "[...] não temos o direito de dizer o que nos apetece, que não podemos falar de tudo em qualquer circunstância, que quem quer que seja, finalmente, não pode falar do que quer que seja." (FOUCAULT, 2004, p. 2).

Essa manipulação do que pode ser dito também interfere na construção de uma reflexão sobre o currículo num momento político conturbado em que apenas um viés de pensamento é valorizado e respeitado. Com a responsabilidade de desatar alguns destes nós entre o discurso oficial de estratégias do saber-poder de um grupo em detrimento das outras vozes, revemos o espaço do currículo escolarizado na formação de professores a partir da formação universitária.

Consideramos que é por meio dos objetivos, das estratégias, da avaliação e das epistemologias que cercam os discursos no currículo e atualmente cerceiam a formação do professor que possamos enxergar de que maneira ocorre a apropriação dos corpos e das mentes nas experiências cotidianas de ensino/aprendizagem nos espaços escolares.

Por ser um caminho de progressão de conteúdos em possíveis conhecimentos de maneira a atender um objetivo específico, o currículo pode adentrar em questões que possam ser avaliadas, revistas e desenvolvidas (SACRISTÁN, 1998, p.46), porém a escolha e a apropriação do que determina um currículo na instituição educacional depende da atuação do professor em consonância ou não com ele.

Como o professor é sujeito pedagógico que, perpassado por múltiplas formações tendo uma influência inclusive de sua formação inicial como base, entendemos que sua apropriação do currículo atravessa ou tende a um percurso de manipulação do conhecimento em saberes específicos e disciplinadores ou à uma busca pela revisão e construção de conheceres.

A depender da formação inicial do professor, ele pode apreender uma forma de uso do currículo em que as tensões e as brechas possam ser aproveitadas de maneira dinâmica ou não, caso sua experiência não 
ISSN 1983-1579

Doi: 10.22478/ufpb.1983-1579.2019v12n3.46682

http://periodicos.ufpb.br/ojs2/index.php

o leve a um outro caminho. Sendo assim, indicamos a práxis, atividade orientada conscientemente em que dimensões objetivas e subjetivas interagem na formação do professor desde a universidade.

A práxis revela não só as teorias que a prática cria ou pode se referir, e sim atua como atividade, é transformadora de sujeitos, objetos e contextos, tal qual Vasquez (1997, p.27) aponta:

[...] entre a teoria e a atividade prática transformadora se insere um trabalho de educação das consciências, de organização dos meios materiais e planos concretos de ação; tudo isso como passagem para indispensável para desenvolver ações reais, efetivas. Nesse sentido uma teoria é prática na medida em que materializa, através de uma série de mediações, o que antes só existia idealmente, como conhecimento da realidade ou antecipação ideal de sua transformação.

Interpretamos a práxis também em acordo com Vázquez (2003, p. 297) sem perder de vista as questões subjetivas, coletivas ou de classe, constituindo-se "uma espécie de corte transversal" dos conceitos que a antecipam ou que posteriormente podem ser revisitados por meio dela. Ampliando os panoramas conceituais, a prática não obedece às necessidades das teorias assim como há teorias que nem sempre se tornaram práticas. A teoria pode refletir sobre a prática diante de uma reflexão contextual em que a História se torna fonte de referenciação.

Inferimos então que o currículo é um órgão educativo vivo por meio da experiência da práxis, é um documento que segue destinos não restritos ao registro, do qual flui questões entrecruzando História e Memória como arcabouços de diferentes olhares. Na perspectiva de práxis, ele é construído nos processos de ensino/aprendizado, caminha por entre funções sociais, históricas e culturais, relacionando no cotidiano entre professores e alunos, projetos de existência de conhecimentos em conteúdos, compartilhando visões específicas de saberes e fazeres.

Neste sentido, concordamos com Neto (2010, p. 61) quando afirma que "é o ser social que materializa o currículo através das práticas pedagógicas, o que torna currículo e ser social uma unidade indissociável.". Desta maneira, processos de ensino/aprendizagem não são termos infalíveis nem protagonizados por receitas premeditadas, mas diante de sua relatividade e contextualização, se tornam processos mediados pela experiência entre conteúdos do concreto ao abstrato, da apresentação, da apresentação à representação.

Destarte, analisar currículos exige um percurso que entende silenciamentos, disputas e principalmente, discursos antagônicos que se refletem na práxis cotidiana das salas de aula. A História que demarca estes processos de construção curricular passa por estratégias de racionalização do espaço e dos indivíduos em adequação e subjugação a desejos do capital econômico, conforme anteriormente citado, em territórios demarcados em espaços do saber-poder.

Abrindo uma brecha para um reaver o currículo contextualmente e, realizando uma analogia com as discussões em Ribeiro (2017), temos como preocupações: na perda de voz do professor, do lugar de fala por uma deseigitimação do pensar/fazer na Educação presa ao movimentos arbitrários e impostos epistemologicamente, expressos desde currículos, mais recentemente na delimitação da experiência em habilidades e competências a serem adquiridas/atingidas conforme cada nível de ensino.

Diante do exposto, este trabalho faz parte de uma investigação iniciada em 2010 e em andamento que busca rever a constituição dos discursos a partir da Educação Tradicional e das políticas educacionais vigentes, assim como interpretar as concepções e denominações (NASCIMENTO, 2005) que evidenciam a 
articulação entre currículo e realidade na práxis.

Como parte da escolarização atual, os currículos são atingidos diretamente pelas políticas educacionais no país, às quais sofreram recentemente uma alteração pelo Conselho Nacional de Educação CNE, nas Diretrizes Curriculares Nacionais - DCNS's de Formação de Professores trazendo à luz não apenas a formação inicial mas a continuada na Resolução ${ }^{\circ}$ 2, de 1 de julho de 2015, previsto no Plano Nacional de Educação - PNE pela Lei Nº 13.005 (2014-2024).

As DCN's de 2015 determinam o prazo de dois anos para que as instituições de nível superior promovam as reformulações curriculares em seus projetos pedagógicos, de acordo com os projetos e planos de desenvolvimento que norteiam cada instituição.

Ao recomendar para a Educação Superior a construção de projetos pedagógicos próximos e dialogantes com a Educação Básica e, a concreta referência da formação de professores com o restante do planejamento de desenvolvimento da instituição, as DCN's de 2015 respondem às lutas das entidades e organizações educacionais, sobre processos mais ativos, coerentes e contextuais de formação para a carreira do magistério.

Por buscar "superar a fragmentação das políticas públicas e a desarticulação institucional" e "o currículo como o conjunto de valores propício à produção e à socialização de significados no espaço social" (DCN's 2015), dentre outros relevantes objetivos considerados, as DCN's de 2015 possuem um cunho que reúne teoria e prática e traduz o movimento para uma práxis efetiva na educação brasileira.

Nesta perspectiva, salientamos que as DCN's de 2015 informam que os currículos devem ser organizados em consonância com a Base Nacional Curricular Comum - BNCC, currículo já bastante questionado em termos de construção crítica efetiva, por ser uma prescrição e uma "seleção comprometida com o eurocentrismo como direitos de aprendizagem [...] uma visão hegemônica burguesa acabou por aprisionar o debate com a atenção voltada para um tecnicismo excludente." (CURY, REIS e ZANARDI, 2018, p.84).

A BNCC é uma base curricular que além da perspectiva destacada acima, tem vários problemas em termos de construção e efetiva participação das instituições educacionais no processo. Percebe-se que apesar de não ser intenção das DCN's 2015 em reproduzir modelos, com a orientação de seguirem a BNCC, são evidentes atualmente os desafios para a construção de novos currículos de cursos de formação de professores, muitos dos quais ainda estão sendo revisados no âmbito das universidades e, de certa forma, permanecem invisíveis nas escolhas e discursos que vão sendo consolidados na escrita curricular.

Além disso, destacamos que é estipulado uma carga horária mínima de 3.200 horas para integralização curricular das licenciaturas, em cursos com duração de, no mínimo, oito semestres ou quatro anos. Assim, os cursos de licenciaturas tiveram o exíguo prazo de dois anos para o debate e reformulação dos currículos dentro dos núcleos, que nas universidades são reconhecidos como Núcleos Docentes Estruturantes - NDE's, instituído por meio da Portaria $N^{\circ} 147$ de 2 de fevereiro de 2007. Pode-se informar que muitos não conseguiram ainda fazer essa readequação e no momento isso pode inclusive se configurar como um posicionamento político diante dos desacertos e retrocessos supracitados.

\section{ENCONTROS NAS LICENCIATURAS EM ARTES VISUAIS - UFBA, UNIVASF E UFOB}

Diante de todo esse panorama e do movimento que pede uma reforma curricular com tão pouco tempo, refletimos sobre algumas discussões realizadas entre 2016 e 2018 sobre os currículos que estão sendo organizados nas licenciaturas na área de Artes Visuais, de universidades públicas no estado da Bahia: Universidade Federal da Bahia - UFBA, Universidade Federal do Vale do São Francisco - UNIVASF e 
ISSN 1983-1579

Doi: 10.22478/ufpb.1983-1579.2019v12n3.46682

http://periodicos.ufpb.br/ojs2/index.php

Universidade Federal do Oeste da Bahia - UFOB.

Utilizamos os currículos na narrativa a seguir como Projetos Pedagógicos de Curso - PPC's, os quais por sua vez pressupõem uma política, uma ética e um estética advindas da práxis de cada contexto referenciado.

Ressaltamos que as impressões a seguir são relatos que visam abordar algumas construções dos cursos desde os NDE's e que estão sendo aprofundadas em pesquisa em andamento sobre as reformas curriculares dos cursos de Licenciatura em Artes Visuais da UFBA, UNIVASF e UFOB e em pesquisas do Observatório de Formação de Professores no âmbito de Ensino de Artes: estudos comparados entre Brasil e Argentina (OFPEA/BRARG) e na Red Latinoamericana de Investigadores sobre Formación de Profesores de Artes (LAIFOPA). Dentre essas pesquisas, convêm citar a pesquisa de SILVA (2017), que analisou a inserção de disciplinas na área de tecnologias digitais a partir dos currículos das licenciaturas em Artes Visuais da região Nordeste.

Em reunião com o grupo do NDE de Artes Visuais da UFBA em abril de 2016 buscamos conectar discursos em construção no NDE da UNIVASF (2009-2016) com a criação e consolidação da Licenciatura em Artes Visuais no semiárido baiano. Sendo assim, tratou-se sobre os processos que constituíram a criação de disciplinas, ementas, como foi pensado o diálogo entre ensino, processos criativos e teoria e história da Arte no PPC vigente àquele período².

A UFBA foi a primeira universidade pública no estado da Bahia e uma das primeiras no Brasil a ter um curso superior de formação na área de Artes Visuais, fundado em Salvador, no litoral baiano, como Academia de Belas Artes em 1877 por Miguel Navarro y Cañizares, com a formação focada nas Belas Artes tal qual a Academia que funcionava no Rio de Janeiro, buscando naquele período a formação de profissionais que atuassem como artistas plásticos.

Apenas em 1983, o antigo curso de Belas Artes sofreu uma reestruturação para o que atualmente é conhecido como Curso de Licenciatura em Desenho e Plástica, impulsionado pela Lei de Diretrizes e Bases da Educação Nacional - LDBEN nº 5692/1971.

Em 2014, a atual Escola de Belas Artes - EBA formou uma comissão para a constituição da reforma dos currículos, de acordo com a Resolução no 01 de 17 de julho de 2010 do Ministério da Educação - MEC, no qual foi instituído o NDE para cada curso que atualmente funciona na EBA/UFBA: Bacharelado em Artes Plásticas, Licenciatura em Desenho e Plástica, além de cursos superiores nas áreas de Decoração e Design.

Em 05 de maio de 2016, com a presença dos integrantes dos NDE's dos diversos cursos da EBA/UFBA e representantes discentes, foi realizado um seminário aberto sobre a reforma curricular da EBA/UFBA com o foco no compartilhamento dos trabalhos em andamento, assim como dar visibilidades às contribuições significativas sobre a construção dos fluxogramas ou grades curriculares apresentados.

Ao final da discussão do grupo do NDE da EBA/UFBA, pelos debates, entendemos que o Curso de Licenciatura em Desenho e Plástica deverá se configurar no período diurno, como Curso de Licenciatura em Artes Visuais com núcleo comum, núcleo contextualizador e núcleo profissional, de forma a articular disciplinas que são comuns aos diversos cursos da EBA/UFBA com os desejos e necessidades de docentes e discentes tanto quanto com o que a legislação determina com o contexto de atuação da EBA/UFBA.

\footnotetext{
${ }^{2}$ Indicamos que em 2019.1 a Licenciatura em Artes Visuais da UNIVASF está migrando para novo PPC em conformidade com as DCN's 2015 e fruto de intenso diálogo entre docentes e discentes do curso.
} 
Atualmente, a EBA/UFBA tem um PPC que foi construído em debate, porém continua em discussões devido a ser necessários revisões de ementas, legislação complementar da própria instituição e também com questões que dependem de outros departamentos, como os de Educação e Filosofia que dispõem disciplinas no currículo da licenciatura em Desenho e Plástica, assim caminhando na ampliação do debate e a escrita desse currículo.

Acerca da UNIVASF, o Curso de Licenciatura em Artes Visuais iniciou suas atividades em agosto de 2009 na cidade de Juazeiro/BA, norte da Bahia, tendo sua estruturação baseada no Relatório do Programa de Reestruturação e Expansão das Universidades Federais - REUNI e do Plano de Desenvolvimento Institucional (PDI) da UNIVASF.

O primeiro Projeto Pedagógico do Curso - PPC da UNIVASF foi finalizado em novembro de 2011. Segundo este documento, o referido curso tem como objetivo atender à demanda de formação inicial de professores de Artes Visuais, sobretudo o acesso à compreensão da produção e da pesquisa em Artes Visuais, articulando teoria e prática em Artes Visuais e em seu ensino.

Entre dezembro de 2015 e dezembro de 2016, o NDE de Artes Visuais da UNIVASF se reuniu com vistas a readequar o PPC de acordo com as DCN's de 2015. Dessas reuniões, um esboço de currículo novo foi sendo trabalhado, em discussões diante de uma série de reuniões mensais, com vistas a expansão necessária das disciplinas de âmbito essencialmente educativo e revisão do espaço das disciplinas que tratavam essencialmente de poéticas artísticas na busca por um diálogo e uma relação de maior proximidade entre as disciplinas.

Dessa maneira, o novo currículo do curso de Licenciatura em Artes Visuais da UNIVASF foi aprovado no NDE, em reunião de colegiado e pela Pró-Reitoria de Ensino -PROEN, com início em 2019.1. Deverá continuar com aulas no período noturno e contar com cinco anos letivos e com mais disciplinas que atingem práticas artístico/educativas, que refletem sobre a diversidade, inclusão, a gestão da educação brasileira. Também aborda os territórios que a Arte Moderna, Contemporânea e o Mercado como temas no ensino artístico.

No Curso de Licenciatura em Artes Visuais da UFOB, o panorama curricular passou primeiramente por uma trajetória de lutas sociais que mobilizou a região do oeste baiano, especialmente a cidade de Santa Maria da Vitória/BA - SAMAVI, culminando com um movimento pró-Campus da UFOB, o qual por sua vez obteve êxito.

A criação do curso de Licenciatura em Artes Visuais da UFOB se deu em 2014 e em agosto do mesmo ano deu início às atividades. Segundo o seu PPC, finalizado em 2016, este curso tem como objetivo a formação de profissionais do magistério em Artes Visuais com fins de exercício do compromisso da educação de crianças, jovens e adultos em espaços formais e não-formais de ensino.

Nos reunimos com os colegas da UFOB em dois momentos, em junho de 2016 e em dezembro de 2018 no campus de SAMAVI. Pudemos perceber no primeiro encontro um currículo já em andamento e uma discussão profícua sobre a formação de professores de Artes Visuais na região. Na segunda ocasião, o encontro foi diretamente com o NDE, pois o grupo de docentes já havia se ampliado, e estavam revendo o currículo do curso, inclusive da possibilidade de migração para o turno noturno.

\section{REVENDO O ESPAÇO DAS LICENCIATURAS EM ARTES VISUAIS NA BAHIA}

Ao rever o espaço do currículo e sua construção, percebe-se que os discursos sobre saberes e fazeres estão presentes nas linhas e entrelinhas, especialmente quando se observa as licenciaturas em Artes Visuais na Bahia. Diante de um histórico de construção da UFBA, da UNIVASF e da UFOB, pode-se inferir que as três 
ISSN 1983-1579

Doi: 10.22478/ufpb.1983-1579.2019v12n3.46682

http://periodicos.ufpb.br/ojs2/index.php

instituições tem seu papel de articulação com a formação já consolidada de professores de Artes Visuais em Salvador.

Tanto UNIVASF quanto UFOB possuem um corpo jovem de professores de diversas regiões do país, fruto das políticas anteriores de interiorização das universidades, diferente da UFBA que, mesmo com a realização de concursos e entrada de alguns professores na renovação do quadro, ainda tem muitas questões que advém de professores mais antigos e de concepções e entendimentos do saber-fazer que se tornaram legado para o currículo e, por essa razão, para a práxis cotidiana nos processos de ensino/aprendizagem.

Por consequência, temos em consideração que as equipes de colegas podem atentar nessa construção e revisão de termos, normas e disciplinas. Dessa maneira, sugerimos a organização de um esquema que possa visualizar os seguintes pontos:

1) Disciplinas que atendem à uma organização cumulativa de saberes, sequenciais;

2) Disciplinas únicas;

3) Disciplinas que se aproximam de outras áreas que não Artes, Artes Visuais, Arte/Educação ou Educação;

4) Disciplinas de cunho essencialmente pedagógico;

5) Disciplinas de cunho essencialmente de poéticas criativas ou processos criativos;

6) Disciplinas de cunho essencialmente teórico, conceitual;

7) Disciplinas hibridizantes que possam atender a uma perspectiva multi, inter e trans.

A classificação que dispomos acima é uma maneira de enxergar as disciplinas, cunhos teórico e metodológico e conceitos que perpassam desde a nomenclatura até a construção dos currículos na práxis dos docentes.Há que se verificar o que pede as DCN's 2015 em termos de carga horária para as disciplinas consideradas essenciais aos cursos de licenciatura, principalmente no que tange ao cunho pedagógico. Essa é uma preocupação que temos observado e percebido nos discursos devido à formação diversificada de docentes que integram estes cursos na UFBA, na UNIVASF e na UFOB.

Mesmo as disciplinas que tratam essencialmente das poéticas criativas ou processos criativos não podem deixar de tratar do uso de materiais e poéticas ou processos nos ambientes educativos formais e não-formais. Todas as disciplinas de uma licenciatura na área de Artes devem repensar o espaço do professor, do estudante e da Educação em Arte.

Entendemos que há um enorme perigo ao tratar uma licenciatura nas disciplinas de poéticas ou processos criativos como um bacharelado. Tanto na formação do bacharel quanto na formação do professor deve-se desde o começo enfatizar a necessidade de construção da ética, do refletir crítico da profissão. Não se pode confundir a formação artística do artista com a formação artística do professor. Este último terá enorme responsabilidade na formação de estudantes, que se refletirá por toda a vida deles, e deve ter uma preparação específica em construções expressivas e criativas em termos de materiais, técnicas, métodos, metodologias, práticas do exercício docente. 
A atenção que mencionamos tem relação direta com uma análise que realizamos no doutoramento (VASCONCELOS, 2015,) que demonstrou algumas relações de desvio e deterioração do fazer docente em Artes Visuais quando o currículo na práxis é revisitado e o docente se utiliza na experiência do ensinar/aprender de uma ênfase do ensino em detrimento de outras. Ao restringir teoricamente uma experiência, o processo de construção do futuro professor de Artes Visuais é atravessado por paradigmas que ao invés de promover a reflexão crítica, podem levar a uma alienação não só no cotidiano das aulas como do constituir-se professor como processo contínuo.

Pelas razões enunciadas, percebemos que o uso de materiais, técnicas, métodos, metodologias, práticas descontextualizados traduz-se em um ensino/aprendizado nos espaços formais e não-formais de ensino que desvaloriza a disciplina Arte, colocando-a à serviço ou de uma instrumentalização técnica, a um livre-fazer, a um saber decorativo ou a um conhecimento aleatório do currículo.

Diante disso, pode-se indicar que os currículos das licenciaturas na área de Artes Visuais da UFBA, UNIVASF e UFOB são parte de uma feitura social, histórica e cultural em que há ao mesmo tempo tensões, conflitos, lutas e silenciamentos. O sistema atual que molda a feitura de um currículo é um sistema adestrador e conforme Boito Junior (2016, p. 25), é fruto de um conflito "distributivo, pela apropriação da riqueza, e ele envolve diversas classes e frações" da sociedade. Em redor das tensões geradas pelas lutas entre as classes, o Estado se torna um rolo compressor que massifica a Educação de maneira conservadora, compactuadas com interesses estrangeiros, com apoio de grupos religiosos e empresários que visam apenas ao lucro e pouco se importam com o futuro do meio ambiente brasileiro.

Neste sentido, concordamos com as visões de Freire (1996) e Giroux (2005), o primeiro por destacar a importância da reflexão crítica sobre a prática na formação de professores, de maneira a reunir e misturar teoria e prática; o segundo por defender que os sujeitos pedagógicos (estudantes e professores) interajam no intuito de questionar ativamente e negociar as relações entre teoria e prática, possibilitando a permeabilidade da análise crítica diante de uma transformação contextualizadora.

Enxergamos ainda um longo caminho a percorrer de forma a lançar pontes entre os currículos da UFBA, UNIVASF e da UFOB, longe de uma uniformidade conforme as políticas educacionais atuais demandam. Não defendemos o distanciamento ou uma oposição mecânica entre capital e interior, porém almejamos a busca de uma sistematização na qual se interprete os locais e suas referências, as demandas estaduais, suas questões, suas reverberações e no futuro quiçá suas relações com o desenvolvimento de outros currículos das licenciaturas em Artes Visuais no Brasil.

A busca pelo diálogo interinstitucional é um passo inicial para entender as dificuldades, os problemas e os desafios que os cursos atravessam em diferentes territórios. A própria Bahia não é unívoca, tem suas peculiaridades e as três instituições assinaladas neste trabalho, sendo uma no litoral, uma no norte e outra no oeste do estado têm trajetórias demarcadas, têm uma história em que ora a influência estrangeira na formação artística exerceu um espaço de dominação perante o currículo, ora as discussões retomavam questões da legislação educacional que as políticas públicas indicavam, ora a comunidade externa trazia suas inquietações e em todos os casos, docentes e estudantes vão construindo um outro currículo bem mais dinâmico.

A este currículo mais dinâmico pode se constituir ao lado de um currículo oculto (SILVA, 2000; 2010), em que os efeitos do ensino/aprendizagem fazem parte de práticas e processos educativos que não são visualizados somente no currículo formal, estão implícitos no cotidiano das aulas.

Apreender como o currículo oculto denota também o currículo oficial dos cursos faz parte do diálogo que procuramos estabelecer nos relatados, mesmo que de forma breve, em alguns entrecruzamentos expressos, a exemplo da comunicação oral no I Encontro do Observatório da formação de professores de 
ISSN 1983-1579

Doi: 10.22478/ufpb.1983-1579.2019v12n3.46682

http://periodicos.ufpb.br/ojs2/index.php

Artes Visuais, realizado entre 01 e 04 de outubro de 2016 em Florianópolis. Esse encontro fez parte também do Encontro da Rede Latinoamericana de Investigadores sobre Formação de Professores de Artes - LAIFOPA e do XII Encontro do Grupo de Pesquisa Educação, Artes e Inclusão, organizado pela professora Doutora Maria Cristina Rosa Fonseca da Silva e demais colaboradores na Universidade do Estado de Santa Catarina UDESC.

Por fim, apontamos que é importante transpor e redesenhar uma conversa que traga uma outra construção curricular, diante da complexidade e de resistências da situação atual em que a formação de professores de Artes Visuais é estratégica, principalmente se refletirmos sobre o desenvolvimento criativo, inovador e crítico dos indivíduos. É necessário que a resiliência seja parte da construção cotidiana desses currículos na Bahia, no desejo de que ao unir as mãos, nós, professores, possamos dialogar mais desde o Brasil à América Latina. Mesmo que todas as crises possam parecer suprimir o que alguns anos de ganhos sociais e discursos descolonialistas conseguiram atingir, estejamos juntos, em amplitude, prontos para riscos mais largos, encontrantes, e em um posicionamento emancipatório, com vez e voz.

\section{REFERÊNCIAS}

BOITO JUNIOR, Armando. Os atores e o enredo da crise política. In: JINKINGS, Ivana; DORIA, Kim; CLETO, Murilo. (Org.). Por que gritamos golpe? Para entender o impeachment e a crise política ano Brasil. São Paulo: Boitempo, 2016.

CURY, Carlos Roberto Jamil.; REIS, Magali. e ZANARDI, Teodoro Adriano Costa. Base Nacional Curricular Comum: dilemas e perspectivas. São Paulo: Cortez, 2018.

FREIRE, Paulo. Pedagogia da Autonomia: saberes necessários à prática educativa. São Paulo: Paz e terra, 1996.

FOUCAULT, Michel. A ordem do discurso. Aula inaugural no College de France, pronunciada em 2 de Dezembro de 1970. São Paulo: Edições Loyola, São Paulo, 2004.

- Microfísica do poder. Tradução Roberto Machado. 24. ed. Rio de Janeiro: Edições

Graal, 2007.

GIROUX, Henry. Qual o papel da pedagogia crítica nos estudos de língua e de cultura? Entrevista com Henry A. Giroux. In: Revista Crítica de Ciências Sociais. n., 73, p. 131-143. dez. 2005. Entrevista concedida a Manuela Guilherme. Disponível em: <www.ces.uc.pt/rccs/includes/download.php?id=911>. Acesso em: 15 de dezembro de 2016.

ILLICH, Ivan. Sociedade sem escolas. São Paulo: Vozes, 1985.

MINISTÉRIO DA EDUCAÇÃO. Conselho Nacional de Educação. Resolução Nº 2, de 1 de julho de 2015. Diretrizes Curriculares Nacionais para a formação inicial em nível superior (cursos de licenciatura, cursos de formação pedagógica para graduados e cursos de segunda licenciatura) e para a formação continuada. DCN's. 2015.2 Disponível em: $<$ http://portal.mec.gov.br/mais-educacao/323-secretarias-112877938/orgaos-vinculados-82187207/21028-resol ucoes-do-conselho-pleno-2015>, acesso em 08 de dezembro de 2015.

NASCIMENTO, Erinaldo Alves do. Mudanças nos nomes da arte na educação: qual infância? que ensino? quem é o bom sujeito docente?. 255f. (Doutorado em Arte Educação), Universidade de São Paulo. São Paulo, 
2005 .

NETO, José Henrique Duarte. A práxis curricular nos cursos de formação de professores da Educação Básica: a epistemologia da prática e a construção do conhecimento escolar. Tese de Doutorado em Educação. Doutorado em Educação Universidade Federal de Pernambuco. Recife, PE: 2010. 330 fls.

RIBEIRO, Djamila. O que é lugar de fala? Belo Horizonte: Letramento; Justificando, 2017.

SACRISTÁN, J. Gimeno. O currículo: uma reflexão sob a prática. Porto Alegre: Artes Médicas, 1998.

SÁNCHEZ, Adolfo Vázquez. A tiempo y destiempo. Antología de ensayos. México: FCE, 2003.

SILVA, Clarissa Santos. Arte, tecnologia e formação docente: reverberações nos currículos das licenciaturas em Artes Visuais da Região Nordeste. 243f. Dissertação (Mestrado). Programa de Pós-Graduação em Artes Visuais. Universidade do Estado de Santa Catarina. Florianópolis, Santa Catarina. 2017.

SILVA, Tomaz Tadeu da. Teoria cultural e educação: um vocabulário crítico. Belo Horizonte: Autêntica, 2000.

Autêntica, 2010. - Documentos de Identidade: Uma Introdução às Teorias de Currículo.Editora

VASCONCELOS, Flávia Maria de Brito Pedrosa. Designare: pontes artístico/educativas na formação docente em Artes Visuais. Lisboa: Chiado editora, 2015.

VAZQUEZ, Adolfo Sanchez. Filosofia da Práxis. 2a edição. Rio de Janeiro: Editora Paz e Terra, 1977.

ZANELLA, Andréa Vieira. Escolarização formal e cidadania: possíveis relações, relações possíveis? In: SILVEIRA, Andréa. F., et al., org. Cidadania e participação social [online]. Rio de Janeiro: Centro Edelstein de Pesquisas Sociais, 2008. pp. 84-91 
ISSN 1983-1579

Doi: 10.22478/ufpb.1983-1579.2019v12n3.46682

http://periodicos.ufpb.br/ojs2/index.php

Recebido em: 10/07/2019

Aceito em: 20/08/2019

Publicado em: 03/10/2019 